\title{
Occupational Risk for Oral Cancer in Nordic Countries
}

\author{
LAURA TARVAINEN $^{1}$, JUHO SUOJANEN ${ }^{2}$, PENTTI KYYRONEN ${ }^{3}$, CHRISTIAN LINDQVIST $^{1,2}$, \\ JAN IVAR MARTINSEN ${ }^{4}$, KRISTINA KJAERHEIM $^{4}$, ELSEBETH LYNGE $^{5}$, PAR SPAREN ${ }^{6}$, \\ LAUFEY TRYGGVADOTTIR $^{7,8}$, ELISABETE WEIDERPASS ${ }^{4,6,9,10}$ and EERO PUKKALA ${ }^{3,11}$ \\ ${ }^{1}$ Department of Oral and Maxillofacial Diseases, University of Helsinki, Helsinki, Finland; \\ ${ }^{2}$ Department of Oral and Maxillofacial Diseases, Helsinki University Hospital, Helsinki, Finland; \\ ${ }^{3}$ Finnish Cancer Registry, Institute for Statistical and Epidemiological Cancer Research, Helsinki, Finland; \\ ${ }^{4}$ Department of Research, Cancer Registry of Norway, \\ Institute of Population-Based Cancer Research, Oslo, Norway; \\ ${ }^{5}$ Department of Public Health, University of Copenhagen, Copenhagen, Denmark; \\ ${ }^{6}$ Department of Medical Epidemiology and Biostatistics, Karolinska Institutet, Stockholm, Sweden; \\ ${ }^{7}$ Icelandic Cancer Registry, Reykjavik, Iceland; \\ ${ }^{8}$ Faculty of Medicine, University of Iceland, Reykjavik, Iceland; \\ ${ }^{9}$ Genetic Epidemiology Group, Folkhälsan Research Center, Helsinki, Finland; \\ ${ }^{10}$ Department of Community Medicine, University of Tromso, The Arctic University of Norway, Tromso, Norway; \\ ${ }^{11}$ School of Health Sciences, University of Tampere, Tampere, Finland
}

\begin{abstract}
Aim: To evaluate occupational risk for cancer of the tongue, oral cavity or pharynx after adjustment for alcohol and tobacco use. Materials and Methods: The data covered 14.9 million people and 28,623 cases of cancer of the tongue, oral cavity and pharynx in the Nordic countries 1961-2005. Alcohol consumption by occupation was estimated based on mortality from liver cirrhosis and incidence of liver cancer. Smoking by occupation was estimated based on the incidence of lung cancer. Results: Only few occupations had relative risks of over 1.5 for cancer of the tongue, oral cavity and pharynx. These occupations included dentists, artistic workers, hairdressers, journalists, cooks and stewards, seamen and waiters. Conclusion: Several occupational categories, including dentists, had an increased relative risk of tongue cancer. This new finding remains to be explained but could be related to occupational chemical exposures, increased consumption of alcohol and tobacco products, or infection with human papilloma virus.
\end{abstract}

There are several occupations that are associated with excess risk of cancer of the tongue, oral cavity or pharynx in

Correspondence to: Laura Tarvainen, Sotilastorpantie 6 b 1, 02680 Espoo, Finland. Tel: +358 503303301, e-mail: laura.tarvainen@fimnet.fi

Key Words: Head and neck cancer, alcohol, tobacco, cancer registry, Nordic countries, epidemiology. different studies (1-6). Lower social class has been related to an increased risk of cancer of the mouth and pharynx in some studies $(4,5,7,8)$, but not in all $(1,9)$. In our previous study, which evaluated the incidence of cancer of the mouth and pharynx in relation to 393 occupational titles and 43 chemical agents in Finland in 1971-95, occupations with high standardized incidence ratios (SIRs) were mostly the ones with high consumption of alcohol (10). Alcohol and tobacco are well-known risk factors for cancer of the mouth and pharynx (11).

The objective of this study, based on data of the Nordic Occupational Cancer (NOCCA) study, was to determine if occupational risk variation exists in cancer of the tongue, oral cavity or pharynx after adjustment for alcohol and tobacco consumption. Alcohol consumption in different occupations was estimated at aggregate level on the basis of mortality from liver cirrhosis and incidence of liver cancer in these categories, available in NOCCA data. Smoking by occupation was estimated based on the incidence of lung cancer.

\section{Materials and Methods}

The NOCCA project presented up to 45 years of cancer incidence data by occupational category for the Nordic populations (12). The data covered 14.9 million people aged 30-64 years in Denmark, Finland, Iceland, Norway and Sweden in the 1960, 1970, 1980/1981 and 1990 censuses. In the NOCCA data, there were 28,623 cases of cancer of the tongue, oral cavity and pharynx in the Nordic countries in 1961-2005, 17,696 in males and 10,927 in females (Table I). 
Table I. Study population (million persons), years of follow-up and number of cancers of tongue, oral cavity and pharynx (excluding nasopharynx) in Nordic countries.

\begin{tabular}{|c|c|c|c|c|c|c|c|c|}
\hline \multirow[b]{2}{*}{ Country } & \multirow[b]{2}{*}{ Study population } & \multirow[b]{2}{*}{ Follow-up } & \multicolumn{2}{|c|}{ Tongue } & \multicolumn{2}{|c|}{ Oral cavity } & \multicolumn{2}{|c|}{ Pharynx } \\
\hline & & & Females & Males & Females & Males & Females & Males \\
\hline Denmark & 2.0 & $1971-2003$ & 530 & 873 & 1230 & 1737 & 704 & 1759 \\
\hline Finland & 3.4 & $1971-2005$ & 839 & 1001 & 836 & 1011 & 510 & 1018 \\
\hline Iceland & 0.1 & $1982-2004$ & 18 & 23 & 38 & 31 & 7 & 25 \\
\hline Norway & 2.6 & $1961-2003$ & 668 & 1201 & 1098 & 1714 & 536 & 1635 \\
\hline Sweden & 6.8 & $1961-2005$ & 1539 & 2329 & 2330 & 3395 & 1534 & 4020 \\
\hline Total & 14.9 & & 3594 & 5427 & 5532 & 7888 & 3296 & 8457 \\
\hline
\end{tabular}

All Nordic countries have a nationwide registration of incident cancer cases during the study period. The registration on new cancer cases is based on notifications from hospitals, private clinics, pathology departments and laboratories. All Nordic countries except Sweden also trace missing cases identified via death certificates. This cohort study was undertaken with linkage of individual records based on the unique personal identity codes used in all Nordic countries. The information on occupation for each person was provided through questionnaires in the censuses and all questionnaires were centrally coded and computerized in the national statistical offices. The original occupational codes were then reclassified into 53 occupational categories and one group of economically inactive persons in the NOCCA study.

Statistical analyses. The relative level of cancer incidence for an occupational category is described by the SIR, with the cancer incidence rates for the entire national study populations used as reference rates. For each country, gender and occupational category, the observed number of cancer cases and person years were stratified in twelve 5-year attained age categories: 30-34, 35-39, 4044, 45-49, 50-54, 55-59, 60-64, 65-69, 70-74, 75-79, 80-84, 85+ years; and 5-year calendar periods. For a given gender, the SIR for a given occupational category in a given country was then calculated as the ratio of the observed and expected numbers.

The relative risks (RR) and their confidence intervals for occupations adjusted for country, age, period, smoking and alcohol use were obtained with the Poisson regression. Country, age and period were categorical variates here, while smoking and alcohol use were continuous ones. Lung cancer incidence was used as proxy variate for smoking. Similarly, mortality from liver cirrhosis and liver cancer incidence were used as proxy variate for alcohol use by occupation.

\section{Results}

Tongue cancer. Males: High SIRs (over 1.50) for tongue cancer in males that were statistically significant were found for waiters, beverage manufacture workers, cooks and stewards, hairdressers, artistic workers, journalists, seamen and economically inactive persons (Table II). Low SIRs (under 0.67 ) that were statistically significant were for male farmers, gardeners and related workers, forestry workers and teachers.
After adjustment for tobacco and alcohol use, RRadj estimates over 1.50 were found for dentists, artistic workers, hairdressers and journalists and were all statistically significant (Table II). As compared to the basic unadjusted estimate of RR, the RR for dentists increased, but all other RRs decreased after adjustment. Adjusted RRs under 0.67 were observed for chimney sweeps and farmers.

Females: In females high SIRs for tongue cancer were found among dentists, artistic workers and fishermen, but none were statistically significant (Table II). Only waiters had SIR over 1.00 that was statistically significant. Low SIRs were found for female launderers and shoe and leather workers, but only the SIR for launderers was statistically significant. After adjustment for tobacco and alcohol use, the only statistically significant RR that was over 1.00 was for teachers. Launderers had low and statistically significant RR.

Oral cavity cancer. Males: High SIRs for oral cavity cancer in males that were statistically significant were found for waiters, cooks and stewards, seamen, beverage manufacture workers, economically inactive persons, artistic workers and journalists (Table III). Low statistically significant SIR was found for farmers. After adjustment for alcohol and tobacco use, only cooks and stewards, waiters and seamen had high and statistically significant RRs. After adjustment, a low RR was found for miners.

Females: In females, high SIRs for oral cavity cancer were found for journalists, waiters, mechanics and launderers (Table III). Low SIRs were found for shoe and leather workers. After adjustment for tobacco and alcohol use, high RRs were found for journalists and waiters.

Pharyngeal (excluding nasopharyngeal) cancer. Males: High SIRs for pharyngeal cancer in males were found for waiters, beverage manufacture workers, cooks and stewards, artistic workers, chimney sweeps, seamen, economically inactive persons and hairdressers (Table IV). Low SIRs were found for farmers, forestry workers, gardeners, teachers, miners and 
Tarvainen et al: Occupational Risk for Oral Cancer

Table II. Observed (Obs) number of tongue cancer cases, standardized incidence ratio (SIR), 95\% confidence interval (95\% CI) in occupations with SIR over 1.50 or under 0.67 for any cancer of mouth and pharynx.

\begin{tabular}{|c|c|c|c|c|c|c|c|c|c|c|}
\hline \multirow[t]{2}{*}{ Occupation } & \multicolumn{5}{|c|}{ Males } & \multicolumn{5}{|c|}{ Females } \\
\hline & Obs & SIR & $95 \% \mathrm{CI}$ & $\mathrm{RR}_{\mathrm{adj}}$ & $95 \% \mathrm{CI}$ & Obs & SIR & $95 \% \mathrm{CI}$ & $\mathrm{RR}_{\mathrm{adj}}$ & $95 \% \mathrm{CI}$ \\
\hline 1 Technical etc. workers & 336 & 0.83 & $0.75-0.92$ & 0.98 & $0.88-1.10$ & 11 & 0.73 & $0.37-1.31$ & 0.76 & $0.42-1.37$ \\
\hline 4 Dentists & 16 & 1.59 & $0.91-2.57$ & 1.75 & $1.07-2.87$ & 6 & 1.76 & $0.65-3.83$ & 1.83 & $0.67-3.98$ \\
\hline 5 Nurses & 0 & & & & & 38 & 0.69 & $0.49-0.95$ & 0.72 & $0.52-0.99$ \\
\hline 8 Teachers & 96 & 0.63 & $0.51-0.76$ & 0.83 & $0.68-1.02$ & 123 & 1.16 & $0.97-1.38$ & 1.23 & $1.03-1.48$ \\
\hline 10 Artistic workers & 56 & 2.05 & $1.55-2.66$ & 1.58 & $1.21-2.06$ & 13 & 1.73 & $0.92-2.96$ & 1.67 & $0.97-2.89$ \\
\hline 11 Journalists & 24 & 1.84 & $1.18-2.75$ & 1.51 & $1.01-2.26$ & $<5$ & & & & \\
\hline 16 Farmers & 283 & 0.51 & $0.45-0.57$ & 0.64 & $0.56-0.73$ & 77 & 0.88 & $0.70-1.10$ & 0.87 & $0.68-1.10$ \\
\hline 17 Gardeners and related workers & 82 & 0.58 & $0.46-0.71$ & 0.71 & $0.57-0.89$ & 95 & 0.86 & $0.69-1.05$ & 0.83 & $0.67-1.04$ \\
\hline 18 Fishermen, whalers, sealers & 40 & 0.68 & $0.49-0.93$ & 0.80 & $0.58-1.10$ & $<5$ & & & & \\
\hline 19 Forestry workers & 62 & 0.59 & $0.45-0.76$ & 0.69 & $0.54-0.89$ & $<5$ & & & & \\
\hline 20 Miners and quarry workers & 23 & 0.88 & $0.56-1.32$ & 0.74 & $0.49-1.12$ & 0 & & & & \\
\hline 21 Seamen & 108 & 1.66 & $1.38-2.01$ & 1.24 & $1.02-1.51$ & 0 & & & & \\
\hline 23 Drivers & 317 & 1.16 & $1.04-1.29$ & 1.11 & $0.99-1.24$ & 7 & 1.21 & $0.49-2.49$ & 1.20 & $0.57-2.53$ \\
\hline 26 Shoe and leather workers & 21 & 1.24 & $0.77-1.90$ & 1.31 & $0.85-2.01$ & 5 & 0.60 & $0.19-1.40$ & 0.55 & $0.18-1.27$ \\
\hline 28 Mechanics and iron and metal ware & 368 & 0.96 & $0.86-1.06$ & 0.93 & $0.83-1.03$ & 13 & 0.82 & $0.44-1.41$ & 0.77 & $0.44-1.33$ \\
\hline 36 Printers and related workers & 58 & 1.28 & $0.98-1.66$ & 0.96 & $0.74-1.25$ & 16 & 1.65 & $0.94-2.68$ & 1.51 & $0.92-2.48$ \\
\hline 39 Beverage manufacture workers & 18 & 3.49 & $2.07-5.51$ & 1.30 & $0.81-2.10$ & $<5$ & & & & \\
\hline 40 Tobacco manufacture workers & $<5$ & & & & & 0 & & & & \\
\hline 43 Engine and motor operator workers & 110 & 0.94 & $0.78-1.13$ & 0.97 & $0.80-1.17$ & $<5$ & & & & \\
\hline 44 Public safety and protection workers & 63 & 0.86 & $0.66-1.09$ & 0.94 & $0.73-1.21$ & 0 & & & & \\
\hline 45 Cooks and stewards & 40 & 2.56 & $1.83-3.49$ & 1.48 & $1.08-2.03$ & 39 & 0.99 & $0.70-1.35$ & 0.97 & $0.71-1.34$ \\
\hline 47 Waiters & 41 & 4.43 & $3.18-6.01$ & 1.22 & $0.85-1.75$ & 55 & 1.39 & $1.05-1.81$ & 1.29 & $0.98-1.71$ \\
\hline 49 Chimney sweeps & 6 & 1.57 & $0.58-3.42$ & 0.38 & $0.14-0.82$ & 0 & & & & \\
\hline 50 Hairdressers & 24 & 2.17 & $1.39-3.23$ & 1.52 & $1.01-2.28$ & 22 & 1.34 & $0.84-2.03$ & 1.31 & $0.86-2.00$ \\
\hline 51 Launderers and dry cleaners & $<5$ & & & & & 10 & 0.50 & $0.24-0.93$ & 0.50 & $0.27-0.93$ \\
\hline 54 Economically-inactive persons & 401 & 1.59 & $1.44-1.75$ & 1.08 & $0.97-1.21$ & 1698 & 0.98 & $0.94-1.03$ & 0.97 & $0.91-1.04$ \\
\hline
\end{tabular}

$\mathrm{RR}_{\mathrm{adj}}$ : Risk ratio adjusted for lung cancer incidence, liver cirrhosis mortality, liver cancer incidence.

public safety and protection workers. After adjustment, high RRs were found for artistic workers, journalists and waiters. Low RRs were found for farmers, miners, forestry workers and gardeners.

Females: In females, high SIRs for pharyngeal cancer that were statistically significant were found for tobacco manufacture workers and waiters (Table IV). Low SIRs were for technical workers, gardeners, teachers and nurses. After adjustment, only artistic workers had high RR, and low RRs were found for technical workers and gardeners.

\section{Discussion}

This study compared the risk of cancer of the mouth and pharynx in different occupations before and after adjustment for tobacco and alcohol use. In most cases, high risk (SIR over 1.5) decreased and low risk (SIR under 0.67) increased after adjustment as expected, because alcohol and tobacco are well-known risk factors for cancer of the mouth and pharynx $(11,13,14)$. However, there were some occupations that showed high risk in different cancer sites after adjustment. These findings need further discussion.

An unexpected finding is the high and statistically significant RR of tongue cancer after adjustment for tobacco and alcohol use in male dentists. A similar finding can also be seen in tongue and pharyngeal cancer for female dentists, although not statistically significant. This high RR for tongue cancer could be an indication of occupational risk factors such as exposure to human papillomavirus (HPV) infection $(15,16)$ due to burr-generated aerosol and salivary contamination. It has been demonstrated that cancerassociated HPVs are especially resistant to surface active disinfectants (17). In addition, chemical compounds including organic solvents and plastic monomers (18) that are commonly used in dentistry, or a higher than average use of alcohol-based mouth rinse (19) may increase the risk for oral cancer in dentists.

Artistic workers had high RRs for tongue cancer in males and for pharyngeal cancer in both genders. Female artistic workers' RRs for tongue and oral cavity cancer were also 
Table III. Observed (Obs) number of oral cavity cancer cases, standardized incidence ratio (SIR), 95\% confidence interval (95\% CI) in occupations with SIR over 1.50 or under 0.67 for any cancer of mouth and pharynx.

\begin{tabular}{|c|c|c|c|c|c|c|c|c|c|c|}
\hline \multirow[t]{2}{*}{ Occupation } & \multicolumn{5}{|c|}{ Males } & \multicolumn{5}{|c|}{ Females } \\
\hline & Obs & SIR & $95 \% \mathrm{CI}$ & $\mathrm{RR}_{\mathrm{adj}}$ & $95 \% \mathrm{CI}$ & Obs & SIR & $95 \% \mathrm{CI}$ & $\mathrm{RR}_{\mathrm{adj}}$ & $95 \% \mathrm{CI}$ \\
\hline 1 Technical etc. workers & 464 & 0.82 & $0.74-0.89$ & 0.95 & $0.86-1.04$ & 18 & 0.90 & $0.53-1.43$ & 0.91 & $0.57-1.45$ \\
\hline 4 Dentists & 15 & 1.02 & $0.57-1.68$ & 1.10 & $0.66-1.83$ & 5 & 1.04 & $0.34-2.42$ & 1.13 & $0.47-2.72$ \\
\hline 5 Nurses & $<5$ & & & & & 72 & 0.89 & $0.70-1.13$ & 0.96 & $0.76-1.21$ \\
\hline 8 Teachers & 149 & 0.70 & $0.60-0.82$ & 0.91 & $0.77-1.07$ & 130 & 0.87 & $0.73-1.03$ & 0.95 & $0.80-1.14$ \\
\hline 10 Artistic workers & 60 & 1.58 & $1.20-2.03$ & 1.19 & $0.92-1.54$ & 17 & 1.62 & $0.95-2.60$ & 1.54 & $0.95-2.48$ \\
\hline 11 Journalists & 28 & 1.57 & $1.04-2.27$ & 1.26 & $0.87-1.83$ & 12 & 2.82 & $1.46-4.92$ & 2.47 & $1.39-4.37$ \\
\hline 16 Farmers & 469 & 0.55 & $0.50-0.60$ & 0.72 & $0.65-0.80$ & 108 & 0.74 & $0.62-0.90$ & 0.87 & $0.71-1.06$ \\
\hline 17 Gardeners and related workers & 146 & 0.68 & $0.58-0.80$ & 0.84 & $0.71-0.99$ & 122 & 0.87 & $0.73-1.04$ & 0.93 & $0.77-1.12$ \\
\hline 18 Fishermen, whalers, sealers & 84 & 0.94 & $0.75-1.16$ & 1.05 & $0.84-1.31$ & $<5$ & & & & \\
\hline 19 Forestry workers & 104 & 0.70 & $0.58-0.85$ & 0.83 & $0.68-1.00$ & $<5$ & & & & \\
\hline 20 Miners and quarry workers & 28 & 0.76 & $0.50-1.10$ & 0.67 & $0.46-0.97$ & 0 & & & & \\
\hline 21 Seamen & 191 & 2.05 & $1.78-2.36$ & 1.60 & $1.38-1.86$ & 0 & & & & \\
\hline 23 Drivers & 363 & 0.94 & $0.85-1.04$ & 0.88 & $0.79-0.98$ & 13 & 1.55 & $0.83-2.65$ & 1.47 & $0.85-4.53$ \\
\hline 26 Shoe and leather workers & 31 & 1.19 & $0.81-1.70$ & 1.24 & $0.87-1.76$ & $<5$ & & & & \\
\hline 28 Mechanics and iron and metal ware & 544 & 0.99 & $0.91-1.08$ & 0.98 & $0.89-1.07$ & 35 & 1.53 & $1.06-2.12$ & 1.29 & $0.92-1.81$ \\
\hline 36 Printers and related workers & 84 & 1.29 & $1.03-1.59$ & 1.00 & $0.81-1.25$ & 17 & 1.24 & $0.72-1.99$ & 1.05 & $0.65-1.69$ \\
\hline 39 Beverage manufacture workers & 16 & 1.84 & $1.05-2.98$ & 0.69 & $0.42-1.14$ & $<5$ & & & & \\
\hline 40 Tobacco manufacture workers & $<5$ & & & & & 7 & 1.92 & $0.77-3.96$ & 1.14 & $0.52-2.48$ \\
\hline 43 Engine and motor operator workers & 150 & 0.94 & $0.80-1.10$ & 0.97 & $0.82-1.14$ & $<5$ & & & & \\
\hline 44 Public safety and protection workers & 104 & 1.00 & $0.83-1.22$ & 1.09 & $0.90-1.32$ & $<5$ & & & & \\
\hline 45 Cooks and stewards & 64 & 3.04 & $2.34-3.88$ & 1.76 & $1.37-2.26$ & 66 & 1.19 & $0.92-1.51$ & 1.17 & $0.92-1.50$ \\
\hline 47 Waiters & 67 & 5.05 & $3.91-6.41$ & 1.57 & $1.18-2.08$ & 113 & 1.96 & $1.63-2.35$ & 1.61 & $1.32-1.96$ \\
\hline 49 Chimney sweeps & 10 & 1.93 & $0.92-3.54$ & 0.57 & $0.29-1.10$ & 0 & & & & \\
\hline 50 Hairdressers & 27 & 1.49 & $0.98-2.16$ & 0.89 & $0.59-1.35$ & 22 & 0.91 & $0.57-1.38$ & 0.84 & $0.55-1.28$ \\
\hline 51 Launderers and dry cleaners & 9 & 0.80 & $0.37-1.52$ & 0.79 & $0.41-1.52$ & 50 & 1.52 & $1.13-2.00$ & 1.42 & $1.07-1.89$ \\
\hline 54 Economically-inactive persons & 596 & 1.73 & $1.60-1.87$ & 1.20 & $1.09-1.31$ & 2754 & 0.98 & $0.95-1.02$ & 1.02 & $0.96-1.07$ \\
\hline
\end{tabular}

$\mathrm{RR}_{\mathrm{adj}}$ : Risk ratio adjusted for lung cancer incidence, liver cirrhosis mortality, liver cancer incidence.

elevated but the results were not statistically significant. Artistic workers are quite a heterogeneous group and include musicians, painters etc. and it is hard to find occupational risk factors that would be common to the majority of artistic occupations. An irregular lifestyle could be one uniting feature for most artistic workers and this could possibly lead to poor oral hygiene, known to be an important risk factor for oral cancer (20). This hypothesis needs further investigation because there is no evidence of poor oral hygiene in artistic workers.

Journalists had high RR, after adjustment for alcohol and tobacco use, in males for tongue and pharyngeal cancer and in females for oral cavity cancer. The RR was aIso high for pharyngeal cancer in females but was not statistically significant. Female journalists had exceptionally high mortality from liver cirrhosis and slightly elevated risk for lung cancer, indicating heavy drinking and moderate tobacco consumption. Male journalists instead had a low lung cancer incidence, moderately elevated mortality from liver cirrhosis and liver cancer incidence, indicating low consumption of tobacco and moderate consumption of alcohol. It is difficult to imagine any specific risk factors for cancer in journalists' work, but they might also have an irregular lifestyle like artistic workers.

Both male and female waiters had elevated RRs for oral cavity cancer and male waiters also for pharyngeal cancer. Irregularities in lifestyle and daily habits due to variable working hours may provide one explanation. The burden of liver diseases among both male and female waiters was found to be up to four-fold greater as compared to the general population and higher than for any other profession (Table V). This indicates significantly high alcohol consumption, which is a risk factor for these cancer types and liver diseases. It is possible that the adjustment method used in our analysis does not work as well with such outlier values as it works with the modest range of variation, and hence we should interpret the adjusted RRs for waiters with certain reservations.

Male hairdressers had a high RR for tongue cancer. Moreover, female hairdressers had a slightly elevated RR for 
Tarvainen et al: Occupational Risk for Oral Cancer

Table IV. Observed (Obs) number of pharynx cancer, standardised incidence ratio (SIR), 95\% confidence interval (95\% CI) in occupations with SIR over 1.50 or under 0.67 for any cancer of mouth and pharynx.

\begin{tabular}{|c|c|c|c|c|c|c|c|c|c|c|}
\hline \multirow[t]{2}{*}{ Occupation } & \multicolumn{5}{|c|}{ Males } & \multicolumn{5}{|c|}{ Females } \\
\hline & Obs & SIR & $95 \% \mathrm{CI}$ & $\mathrm{RR}_{\mathrm{adj}}$ & $95 \% \mathrm{CI}$ & Obs & SIR & $95 \% \mathrm{CI}$ & $\mathrm{RR}_{\mathrm{adj}}$ & $95 \% \mathrm{CI}$ \\
\hline 1 Technical etc. workers & 471 & 0.74 & $0.67-.081$ & 0.91 & $0.83-1.00$ & 5 & 0.39 & $0.13-0.90$ & 0.39 & $0.13-0.92$ \\
\hline 4 Dentists & 10 & 0.62 & $0.30-1.13$ & 0.73 & $0.39-1.36$ & 5 & 1.78 & $0.58-4.14$ & 1.85 & $0.60-4.31$ \\
\hline 5 Nurses & $<5$ & & & & & 32 & 0.65 & $0.45-0.92$ & 0.71 & $0.50-1.01$ \\
\hline 8 Teachers & 139 & 0.58 & $0.49-0.69$ & 0.87 & $0.73-1.03$ & 60 & 0.64 & $0.49-0.82$ & 0.70 & $0.54-0.90$ \\
\hline 10 Artistic workers & 108 & 2.57 & $2.10-3.10$ & 1.93 & $1.60-2.34$ & 12 & 1.89 & $0.98-3.30$ & 1.80 & $1.02-3.18$ \\
\hline 11 Journalists & 39 & 1.40 & $1.40-2.67$ & 1.54 & $1.12-2.11$ & 6 & 2.21 & $0.81-4.82$ & 1.90 & $0.70-4.14$ \\
\hline 16 Farmers & 270 & 0.32 & $0.29-0.36$ & 0.45 & $0.40-0.51$ & 52 & 0.71 & $0.53-0.93$ & 0.84 & $0.63-1.11$ \\
\hline 17 Gardeners and related workers & 105 & 0.48 & $0.39-0.58$ & 0.65 & $0.54-0.79$ & 43 & 0.64 & $0.46-0.86$ & 0.66 & $0.48-0.90$ \\
\hline 18 Fishermen, whalers, sealers & 64 & 0.75 & $0.58-0.96$ & 0.85 & $0.67-1.09$ & 0 & & & & \\
\hline 19 Forestry workers & 56 & 0.37 & $0.28-0.48$ & 0.45 & $0.35-0.59$ & 0 & & & & \\
\hline 20 Miners and quarry workers & 23 & 0.59 & $0.37-0.89$ & 0.45 & $0.30-0.68$ & 0 & & & & \\
\hline 21 Seamen & 210 & 2.19 & $1.90-2.51$ & 1.43 & $1.24-1.65$ & 0 & & & & \\
\hline 23 Drivers & 477 & 1.14 & $1.04-1.25$ & 1.05 & $0.96-1.15$ & 5 & 0.92 & $0.30-2.14$ & 0.86 & $0.28-2.01$ \\
\hline 26 Shoe and leather workers & 32 & 1.22 & $0.84-1.73$ & 1.31 & $0.92-1.85$ & 9 & 1.41 & $0.64-2.67$ & 1.30 & $0.68-2.51$ \\
\hline 28 Mechanics and iron and metal ware & 604 & 1.00 & $0.92-1.09$ & 0.96 & $0.89-1.05$ & 17 & 1.17 & $0.68-1.87$ & 0.99 & $0.61-1.60$ \\
\hline 36 Printers and related workers & 91 & 1.26 & $1.02-1.55$ & 0.90 & $0.73-1.11$ & 6 & 0.76 & $0.28-1.65$ & 0.66 & $0.29-1.46$ \\
\hline 39 Beverage manufacture workers & 31 & 3.29 & $2.24-4.67$ & 1.08 & $0.75-1.55$ & $<5$ & & & & \\
\hline 40 Tobacco manufacture workers & $<5$ & & & & & 6 & 2.74 & $1.01-5.97$ & 1.25 & $0.46-2.72$ \\
\hline 43 Engine and motor operator workers & 148 & 0.85 & $0.72-1.00$ & 0.86 & $0.73-1.01$ & 5 & 2.72 & $0.88-6.34$ & 1.29 & $0.42-3.02$ \\
\hline 44 Public safety and protection workers & 74 & 0.66 & $0.52-0.83$ & 0.74 & $0.59-0.93$ & $<5$ & & & & \\
\hline 45 Cooks and stewards & 64 & 2.71 & $2.09-3.46$ & 1.37 & $1.07-1.76$ & 25 & 0.88 & $0.57-1.29$ & 0.84 & $0.56-1.25$ \\
\hline 47 Waiters & 98 & 6.68 & $5.42-8.14$ & 1.50 & $1.19-1.92$ & 49 & 1.56 & $1.15-2.06$ & 1.25 & $0.94-1.69$ \\
\hline 49 Chimney sweeps & 14 & 2.45 & $1.34-4.11$ & 0.58 & $0.33-1.01$ & 0 & & & & \\
\hline 50 Hairdressers & 32 & 1.70 & $1.16-2.40$ & 1.02 & $0.71-1.47$ & 21 & 1.45 & $0.90-2.21$ & 1.31 & $0.84-2.03$ \\
\hline 51 Launderers and dry cleaners & 12 & 1.03 & $0.53-1.80$ & 0.94 & $0.53-1.65$ & 11 & 0.63 & $0.31-1.12$ & 0.60 & $0.33-1.09$ \\
\hline 54 Economically-inactive persons & 809 & 2.05 & $1.91-2.20$ & 1.41 & $1.30-1.53$ & 1506 & 0.99 & $0.94-1.05$ & 1.05 & $0.97-1.13$ \\
\hline
\end{tabular}

$\mathrm{RR}_{\mathrm{adj}}$ : risk ratio adjusted for lung cancer incidence, liver cirrhosis mortality, liver cancer incidence.

tongue cancer, but this was not statistically significant. It is possible that an elevated RR for tongue cancer after adjustment for tobacco and alcohol use in hairdressers is due to occupational risk factors because there is evidence of occupation-related risk excess among hairdressers for other cancer types. For example, the risk of bladder cancer was elevated at least for hairdressers working before the 1980s when aromatic amines were used in hair dyes (21). Risk for laryngeal cancer, lung cancer and multiple myeloma were also elevated according to some studies (22). Hairdressers are exposed to many chemicals in hair products and the International Agency for Research on Cancer (IARC) has classified "occupational exposures of hairdressers and barbers" as probably carcinogenic to humans (23).

Male cooks and stewards had a high RR for oral cavity cancer and slightly elevated RR for tongue and pharyngeal cancer. Female cooks and stewards did not have statistically elevated RRs for any cancer of the mouth and pharynx. Cooks have been demonstrated as having higher risk of oral cancer. A possible explanation for elevated risk can be exposure to cooking oil fumes (24). In addition, continuous exposure to fermentable starch and sugars during tasting is a known risk factor for caries, which can lead to elevated acetaldehyde levels in the oral cavity. The IARC recently stated that consumption of very hot beverages increases the risk for esophageal cancer (25). Whether continuous tasting of hot foods also increases the risk for oral cancer remains to be investigated.

Seamen had on elevated RR for oral cavity cancer, and their RR for tongue and pharyngeal cancer was moderately elevated. At the same time, fishermen had a decreased RR, indicating that the working environment at sea is not an explanation, but instead the explanation for elevated risk among seamen may be an irregular lifestyle and numerous intimate relationships which could lead to higher HPV prevalence.

After adjustment for alcohol and tobacco use, male farmers had low RRs for tongue and pharynx cancer. The RR for oral cavity cancer was also quite low in this group. Farmers live a very regular life and probably eat vegetables and fruits more than average. In Finland, only office workers eat more fresh vegetables than farmers (26). High 
Table V. Standardized incidence ratio (SIR) of lung and liver cancer and standardized mortality ratio (SMR) of liver disease in occupations with SIR over 1.50 or under 0.67 for any cancer of mouth and pharynx.

\begin{tabular}{|c|c|c|c|c|c|c|}
\hline \multirow[b]{2}{*}{ Occupation } & \multicolumn{2}{|c|}{ Lung cancer, SIR } & \multicolumn{2}{|c|}{ Liver disease, SMR } & \multicolumn{2}{|c|}{ Liver cancer, SIR } \\
\hline & Males & Females & Males & Females & Males & Females \\
\hline 1 Technical etc. workers & 0.82 & 0.98 & 0.58 & 0.62 & 0.87 & 0.77 \\
\hline 4 Dentists & 0.50 & 0.61 & 0.80 & 0.45 & 0.98 & 0.97 \\
\hline 5 Nurses & 0.40 & 0.69 & 0.80 & 0.45 & 0.83 & 0.92 \\
\hline 8 Teachers & 0.49 & 0.55 & 0.45 & 0.53 & 0.69 & 0.74 \\
\hline 10 Artistic workers & 0.93 & 1.01 & 1.72 & 1.55 & 1.41 & 1.21 \\
\hline 11 Journalists & 0.93 & 1.37 & 1.25 & 3.02 & 1.95 & 0.62 \\
\hline 16 Farmers & 0.56 & 0.46 & 0.31 & 0.12 & 0.47 & 0.66 \\
\hline 17 Gardeners and related workers & 0.68 & 0.54 & 0.64 & 0.31 & 0.66 & 0.83 \\
\hline 18 Fishermen, whalers, sealers & 1.16 & 0.89 & 0.55 & - & 0.78 & 1.31 \\
\hline 19 Forestry workers & 0.88 & 1.06 & 0.63 & 0.85 & 0.69 & 0.70 \\
\hline 20 Miners and quarry workers & 1.58 & 0.65 & 1.36 & - & 1.17 & - \\
\hline 21 Seamen & 1.62 & 0.47 & 1.64 & - & 1.80 & - \\
\hline 23 Drivers & 1.28 & 1.46 & 0.96 & 0.94 & 1.22 & 1.04 \\
\hline 26 Shoe and leather workers & 1.06 & 1.09 & 0.91 & 0.82 & 1.08 & 1.19 \\
\hline 28 Mechanics and iron and metal ware & 1.24 & 1.60 & 0.99 & 1.17 & 1.00 & 1.14 \\
\hline 36 Printers and related workers & 1.20 & 1.71 & 1.39 & 2.11 & 1.39 & 1.38 \\
\hline 39 Beverage manufacture workers & 1.42 & 1.88 & 3.40 & 2.18 & 2.50 & 1.37 \\
\hline 40 Tobacco manufacture workers & 1.79 & 2.33 & 1.99 & 1.47 & 1.96 & 2.04 \\
\hline 43 Engine and motor operator workers & 1.20 & 2.61 & 0.81 & 1.43 & 1.13 & 1.39 \\
\hline 44 Public safety and protection workers & 0.97 & 1.23 & 0.69 & 2.04 & 1.12 & 0.37 \\
\hline 45 Cooks and stewards & 1.56 & 1.13 & 2.53 & 1.19 & 2.60 & 1.07 \\
\hline 47 Waiters & 1.90 & 1.89 & 3.48 & 2.50 & 4.22 & 1.36 \\
\hline 49 Chimney sweeps & 1.49 & - & 1.44 & - & 1.57 & - \\
\hline 50 Hairdressers & 1.22 & 1.30 & 1.99 & 1.15 & 1.43 & 1.15 \\
\hline 51 Launderers and dry cleaners & 1.28 & 1.25 & 0.75 & 0.93 & 1.13 & 1.27 \\
\hline 54 Economically inactive persons & 1.33 & 0.94 & 2.59 & 0.98 & 1.54 & 1.02 \\
\hline
\end{tabular}

consumption of vegetables and fruits reduces the risk of oral and pharyngeal cancer (27).

Male forestry workers had a low RR for pharyngeal cancer and quite low RR for tongue and oral cavity cancer after adjustment for tobacco and alcohol use. There is no evidence of consumption of healthier food or other protective agents that could explain this finding, hence it needs further study.

Male chimney sweeps and miners had low RRs for oral and pharyngeal cancer after adjustment for tobacco and alcohol use. It is hard to believe that consumption of protective agents such as fruits and vegetables play a role in these occupations. However, there seem to be some occupational risk factors that cause lung cancer, other than smoking. Exposure to soot among chimney sweeps (28), radon, dust exposure (29) and diesel exhaust among miners (30) are possible risk factors for lung cancer. Accumulation of multiple risk factors for lung cancer can cause overadjustment of the SIR for oral and pharyngeal cancer. Therefore in these professions, a low RR for oral and pharyngeal cancer is possibly a statistical artefact.
The low RR for tongue cancer for female launderers might be explained by a similar mechanism as above; higher rates of lung cancer due to occupational exposure to solvent vapors can cause over-adjustment of the SIR for oral and pharyngeal cancer (31). Similar elevated occupational risk for lung cancer may also explain shoe and leather workers' low RR of oral cavity cancer (32) since their working conditions or socio-economic status presumably does not significantly differ from those of clothing industry workers whose risk for tongue cancer is not changed.

The strengths of this study include the large number of cases during the 45 years of follow-up, reliable diagnoses with virtually full coverage of cancer cases $(33,34)$, and the high accuracy of occupational codes (12). The unique personal identity codes in all Nordic countries used as keys in linkage between the census data, mortality and emigration data, and cancer registries guarantee accurate linkages. Occupational information was based on national censuses from 1960 to 1990 . Validity studies indicate that the classification by occupation in the Nordic censuses is reasonably accurate (12). The extent to which the first 
census occupation reflects the lifetime experience varies considerably across occupational categories. Occupational stability is considered most stable in the early decades of follow-up and it is higher among men than women and highest in occupational categories where a long education is required, such as for physicians, dentists and teachers $(35,36)$. A limitation of this study is the absence of individual data on risk behavior factors such as smoking and consumption of alcohol, as well as HPV infection or oral hygiene. The adjustment method using lung cancer and liver disease mortality and liver cancer incidence seems to work adequately for most occupations since the RRs are closer to 1.00 than SIRs. However, we cannot rule-out the possibility of residual confounding by risk factors such as smoking and alcohol, that could explain risk in some professional categories particularly exposed to those products.

The main result of this study is that after adjustment for alcohol and tobacco use, the only individuals that had elevated RRs were dentists, artistic workers, hairdressers, journalists, cooks and stewards, seamen and waiters. For dentists, we speculate that occupational exposure to HPV or chemical compounds including organic solvents and plastic monomers may have a greater role than expected. Identification of specific occupational risk factors for these professions requires separate in-depth studies.

\section{Conflicts of Interest}

The Authors declare no potential conflicts of interest with respect to the authorship and publication of this article.

\section{Acknowledgements}

This work was sponsored by the Nordic Cancer Union and Cancer Society of Finland. The study sponsor had no role in design, analysis or reporting of the results of the study.

\section{References}

1 Pukkala E, Söderholm AL and Lindqvist C: Cancers of the lip and oropharynx in different social and occupational groups in Finland. Eur J Cancer B Oral Oncol 30B(3): 209-215, 1994.

2 Merletti F, Boffetta P, Ferro G, Pisani P and Terracini B: Occupation and cancer of the oral cavity or oropharynx in Turin, Italy. Scand J Work Environ Health 17(4): 248-254, 1991.

3 Winn DM, Blot WJ, Shy CM and Fraumeni JF Jr.: Occupation and oral cancer among women in the South. Am J Ind Med 3(2): 161-167, 1982.

4 Arias Bahia SH, Echenique Mattos I and Koifman S: Cancer and wood-related occupational exposure in the Amazon region of Brazil. Environ Res 99(1): 132-140, 2005.

5 Purdue MP, Järvholm B, Bergdahl IA, Hayes RB and Baris D: Occupational exposures and head and neck cancers among Swedish construction workers. Scand J Work Environ Health 32(4): 270-275, 2006.
6 Krstev S, Stewart P, Rusiecki J and Blair A: Mortality among shipyard Coast Guard workers: a retrospective cohort study. Occup Environ Med 64(10): 651-658, 2007.

7 Conway DI, McKinney PA, McMahon AD, Ahrens W, Schmeisser N, Benhamou S, Bouchardy C, Macfarlane GJ, Macfarlane TV, Lagiou P, Minaki P, Bencko V, Holcátová I, Merletti F, Richiardi L, Kjaerheim K, Agudo A, Castellsague X, Talamini R, Barzan L, Canova C, Simonato L, Lowry RJ, Znaor A, Healy CM, McCartan BE, Marron M, Hashibe M and Brennan P.: Socioeconomic factors associated with risk of upper aerodigestive tract cancer in Europe. Eur J Cancer 46(3): 588-598, 2010.

8 Johnson S, McDonald JT and Corsten MJ: Socioeconomic factors in head and neck cancer. J Otolaryngol Head Neck Surg 37(4): 597-601, 2008.

9 Conway DI, McMahon AD, Smith K, Black R, Robertson G, Devine J and McKinney PA: Components of socioeconomic risk associated with head and neck cancer: A population-based casecontrol study in Scotland. Br J Oral Maxillofac Surg 48(1): 11$17,2010$.

10 Tarvainen L, Kyyrönen P, Kauppinen T and Pukkala E: Cancer of the mouth and Pharynx, occupation and exposure to chemical agents in Finland [in 1971-95]. Int J Cancer 123(3): 653-659, 2008.

11 Ernani V and Saba NF: Oral cavity cancer: risk factors, pathology, and management. Oncology 89(4): 187-195, 2015.

12 Pukkala E, Martinsen JI, Lynge E, Gunnarsdottir HK, Sparén P, Tryggvadottir L, Weiderpass E and Kjærheim K: Occupation and cancer - follow-up of 15 million people in five Nordic Countries. Acta Oncol 48(5): 646-790, 2009.

13 Tarvainen L, Suuronen R, Lindqvist C and Malila N: Is the incidence of oral and pharyngeal cancer increasing in Finland? An epidemiological study of 17,383 cases in 1953-1999. Oral Diseases 10(3): 167-172, 2004.

14 Radoï L, Menvielle G, Cyr D, Lapôtre-Ledoux B, Stücker I and Luce D; ICARE Study Group: Population attributable risks of oral cavity cancer to behavioral and medical risk factors in France: results of a large population-based case-control study, the ICARE study. BMC Cancer 15: 827, 2015.

15 D'Souza G, Kreimer AR, Viscidi R, Pawlita M, Fakhry C, Koch WM, Westra WH and Gillison ML: Case-control study of human papillomavirus and oropharyngeal cancer. N Engl J Med 356(19): 1944-1956, 2007.

16 Tran N, Rose BR and O'Brien CJ: Role of human papillomavirus in the etiology of head and neck cancer. Head Neck 29(1): 64-70, 2007.

17 Meyers J, Ryndock E, Conway MJ and Meyers C, Robison R: Susceptibility of high-risk human papillomavirus type 16 to clinical disinfectants. J Antimicrob Chemother 64(6): 1546-1550, 2014.

18 Shi T, Zhao C, Li Z, Zhang Q and Jin X: Bisphenol a exposure promotes the migration of NCM460 cells via estrogen receptormediated integrin $31 / \mathrm{MMP}-9$ pathway. Environ Toxicol 31(7): 799-807, 2016.

19 Guha N, Boffetta P, Wünsch-Filho V, Eluf-Neto J, Shangina O and Zaridze D: Oral health and risk of squamous cell carcinoma of the head and neck and esophagus: results of two multicentric case-control studies. Am J Epidemiol 166(10): 1159-1173, 2007.

20 Homann N, Tillonen J, Rintamäki H, Salaspuro M, Lindqvist C and Meurman JH: Poor dental status increases acetaldehyde production from ethanol in saliva: a possible link to increased oral cancer risk among heavy drinkers. Oral Oncol 37(2): 153158,2001 
21 Harling M, Schablon A, Schedlbauer G, Dulon M and Nienhaus A: Bladder cancer among hairdressers: a meta-analysis. Occup Environ Med 67(5): 351-358, 2010.

22 Bahi Takkouche, Carlos Regueira-Méndez, and Agustín MontesMartínez: Risk of cancer among hairdressers and related workers: a meta-analysis Int J Epidemiol 38(6): 1512-1531, 2009.

23 International Agency for Research on Cancer: Occupational exposures of hairdressers and barbers and personal use of hair colourants. In: Some Aromatic Amines, Organic Dyes, and Related Exposures. IARC Monogr Eval Carcinog Risks Hum 99: 499-658, 2010.

24 He B, Chen F, Yan L, Huang J, Liu F, Qiu Y, Lin L, Zhang Z, Cai L: Independent and joint exposure to passive smoking and cooking oil fumes on oral cancer in Chinese women: a hospitalbased case-control study. Acta Otolaryngol 136(10): 1074-1078, 2016.

25 Loomis D, Guyton KZ, Grosse Y, Lauby-Secretan B, El Ghissassi F, Bouvard V, Benbrahim-Tallaa L, Guha N, Mattock $\mathrm{H}$, Straif K; International Agency for Research on Cancer Monograph Working Group: Carcinogenicity of drinking coffee, mate, and very hot beverages. Lancet Oncol 17: 877-878, 2016.

26 Helakorpi S, Uutela A, Prättälä R and Puska P: Health Behaviour and Health among Finnish Adult Population, Spring 1999. Kansanterveyslaitoksen julkaisuja B19. ISBN 951-740153-1, 1999.

27 Levi F, Pasche C, La Vecchia C, Lucchini F, Franceschi S and Monnier P: Food groups and risk of oral and pharyngeal cancer. Int J Cancer 77(5): 705-709, 1998.

28 International Agency for Research on Cancer: Carbon Black, Titanium Dioxide, and Talc. IARC Monogr Eval Carcinog Risks Hum 93: 1-413, 2010.
29 Mashammer $\mathrm{H}$ and Neuberger M: Lung cancer and dust exposure: results of a prospective cohort study following 3260 workers for 50 years. Occup Environ Med 61(2): 157-162, 2004.

30 Silverman DT, Samanic CM and Lubin JH: The diesel exhaust in miners study: a nested case-control study of lung cancer and diesel exhaust. J Natl Cancer Ins 104(11): 855-868, 2012.

31 Blair A, Decoufle P and Grauman D: Causes of death among laundry and dry cleaning workers. Am J Public Health 69(5): 508-511, 1979

32 Rastogi SK, Kesavachandran C, Mahdi F and Pandey A: Occupational cancers in leather tanning industries: A short review. Indian J Occup Environ Med 11(1): 3-5, 2007.

33 Teppo L, Pukkala E and Lehtonen M: Data quality and quality control of a population-based cancer registry. Experience in Finland. Acta Oncol 33(4): 365-369, 1994.

34 Larsen IK, Småstuen M, Johannesen TB, Langmark F, Parkin DM, Bray F and Møller B: Data quality at the Cancer Registry of Norway: an overview of comparability, completeness, validity and timeliness. Eur J Cancer 45(7): 1218-1231, 2009.

35 Meurman LO, Pukkala E and Hakama M: Incidence of cancer among anthophyllite asbestos miners in Finland. Occup Environ 51(6): 421-425, 1994.

36 Notkola V, Pajunen A and Leino-Arjas P: Occupational Mortality by Cause in Finland 1971-1991 and Occupational Mobility. SVT Health, Vol 1. Helsinki (Finland): Statistics Finland, 1997.

Received April 3, 2017

Revised April 17, 2017

Accepted April 19, 2017 